OPEN ACCESS

Edited by:

Boris Rewald,

University of Natural Resources and

Life Sciences, Vienna, Austria

Reviewed by:

Olga M. C. C. Ameixa,

University of Aveiro, Portugal

Ze-Xin Fan,

Xishuangbanna Tropical Botanical

Garden (CAS), China

*Correspondence:

Zhenying Huang

zhenying@ibcas.ac.cn

Specialty section:

This article was submitted to

Functional Plant Ecology,

a section of the journal

Frontiers in Plant Science

Received: 03 December 2016

Accepted: 29 May 2017

Published: 16 June 2017

Citation:

Yang F, Baskin JM, Baskin CC, Yang X, Cao D and Huang Z (2017)

Divergence in Life History Traits

between Two Populations of a

Seed-Dimorphic Halophyte

in Response to Soil Salinity.

Front. Plant Sci. 8:1028.

doi: 10.3389/fpls.2017.01028

\section{Divergence in Life History Traits between Two Populations of a Seed-Dimorphic Halophyte in Response to Soil Salinity}

\author{
Fan Yang ${ }^{1,2}$, Jerry M. Baskin ${ }^{3}$, Carol C. Baskin ${ }^{3,4}$, Xuejun Yang ${ }^{1}$, Dechang Cao ${ }^{1}$ and \\ Zhenying Huang ${ }^{1 *}$
}

${ }^{1}$ State Key Laboratory of Vegetation and Environmental Change, Institute of Botany, Chinese Academy of Sciences, Beijing, China, ${ }^{2}$ Institute of Sericulture, Chengde Medical University, Chengde, China, ${ }^{3}$ Department of Biology, University of Kentucky, Lexington, KY, United States, ${ }^{4}$ Department of Plant and Soil Sciences, University of Kentucky, Lexington, KY, United States

Production of heteromorphic seeds is common in halophytes growing in arid environments with strong spatial and temporal heterogeneity. However, evidence for geographic variation (reflecting local adaptation) is almost nonexistent. Our primary aims were to compare the life history traits of two desert populations of this halophytic summer annual Suaeda corniculata subsp. mongolica and to investigate the phenotypic response of its plant and heteromorphic seeds to different levels of salt stress. Dimorphic seeds $\left(F_{1}\right)$ of the halophyte $S$. corniculata collected from two distant populations $\left(F_{0}\right)$ that differ in soil salinity were grown in a common environment under different levels of salinity to minimize the carryover effects from the field environment and tested for variation in plant $\left(F_{1}\right)$ and seed $\left(F_{2}\right)$ traits. Compared to $F_{1}$ plants grown in low soil salinity, those grown in high salinity $\left(>0.2 \mathrm{~mol} \cdot \mathrm{L}^{-1}\right)$ were smaller and produced fewer seeds but had a higher reproductive allocation and a higher non-dormant brown seed: dormant black seed ratio. High salinity during plant growth decreased germination percentage of $F_{2}$ black seeds but had no effect on $F_{2}$ brown seeds. Between population differences in life history traits in the common environment corresponded with those in the natural populations. Phenotypic differences between the two populations were retained in $F_{1}$ plants and in $F_{2}$ seeds in the common environment, which suggests that the traits are genetically based. Our results indicate that soil salinity plays an ecologically important role in population regeneration of $S$. corniculata by influencing heteromorphic seed production in the natural habitat.

\footnotetext{
Keywords: halophyte, plant life history traits, population divergence, reproductive allocation, seed germination, seed heteromorphism, seed morph ratio
}

\section{INTRODUCTION}

In arid and semi-arid regions of the world, soil salinity is an environmental stress factor to plants, partly because soil conditions are strongly heterogeneous in space and time (Bernstein, 1975). Much work on halophytic species has focused on their morphology, photosynthesis, physiology and molecular biology in an attempt to understand their distinctive adaptations to 
saline environments (Bernstein, 1975; Zhu, 2001; RedondoGómez et al., 2006; Pandolfi et al., 2012). Fluctuations in soil salinity potentially can result in high mortality in the germinating seed cohorts, and therefore high salt tolerance of seeds of halophytes during the germination stage has been studied (Ungar, 1978; Khan and Gul, 2006; Ameixa et al., 2016). As a link between two generations, seeds traits have a direct impact on population regeneration and dynamics (Harper, 1977; Donohue, 2009). Seed dormancy and germination responses enable seedling populations to emerge at the right time under relatively favorable environmental conditions that ensure establishment and completion of the life cycle (Hoyle et al., 2015; Huang et al., 2016). Therefore, seed traits and subsequent growth strategy are important for seedling survival and reproductive success in arid and saline habitats (Ungar, 1987; Gutterman, 2002; Yang et al., 2012).

Seed heteromorphism, i.e., the production by a single plant of two or more seed morphs that differ in mass, morphology, and ecology, is prevalent in arid habitats, and it is particularly common in halophytes (Khan and Ungar, 2001; Imbert, 2002). Harper (1977) hypothesized that seed heteromorphism confers a selective advantage to plants that grow in extreme, fluctuating environments, for example because different seed morphs may germinate at different times due to differences in dormancy and seed coat properties (Mohamed-Yasseen et al., 1994; Baskin and Baskin, 2014). A prolonged overall germination period enabled by the combination of different seed morphs may provide more opportunities for establishment of seedling cohorts than monomorphic morphs by spreading the risks of survival in variable environments (Venable, 1985a; Venable et al., 1987). Heteromorphic seeds not only have distinct dormancy/germination behaviors (Mandák and Pyšek, 1999; Wang et al., 2008; Yao et al., 2010; Cao et al., 2012; Baskin and Baskin, 2014), but plants growing from them can differ in various life history traits such as survival and biomass allocation (Sorensen, 1978; Mandák and Pyšek, 2005; Ruiz de Clavijo, 2005; Wang et al., 2012; Baskin and Baskin, 2014; Yang et al., 2015a). Thus, the relative production of different seed morphs can be used to predict germination behavior and adaptive strategy of a heteromorphic population (Venable et al., 1995).

Variation in seed (and seedling) traits of seed-heteromorphic halophytes occurs among populations (Ladiges et al., 1981; Song et al., 2008). However, evidence for geographic variation (reflecting local adaptation) is almost nonexistent probably because the carryover effects of field environments have not been ruled out in most studies. By investigating natural populations, any phenotypic differences between them can be distinguished. Further, by rearing plants from different habitats in a common environment under different levels of salinity, we can remove the effects of the natural (maternal) environment and test the phenotypic plasticity response of heteromorphic seeds to soil salinity. We previously reported that maternal soil salinity can affect heteromorphic seed germination and seedling growth (Yang et al., 2015b), but our knowledge of seed morph production is much lower than that of other life history traits influenced by soil salinity. Here, we hypothesized that (1) phenotypic differences occur between populations in the field; (2) these differences in plants and seed traits between populations are genetically based; and (3) seed morph production and germination behavior of heteromorphic seeds are influenced by the magnitude of soil salinity. We tested our hypothesis using two distant populations (about $1700 \mathrm{~km}$ away from each other in northern China) of the halophyte Suaeda corniculata (C. A. Meyer) Bunge subsp. mongolica Lomon. \& Freitag (Amaranthaceae) (hereafter Suaeda corniculata), which differ strongly in habitat soil salinity regime.

Suaeda corniculata is a succulent summer annual herb that grows in saline-alkaline soils (Zhu et al., 2003) and is widely distributed in steppes and semiarid and arid zones of northern China, Mongolia and south-central Siberia (Lomonosova et al., 2008). It produces two diaspore morphs: brown and black seeds. The brown seeds are non-dormant, whereas the black seeds are dormant and can exhibit an annual dormancy/non-dormancy cycling in the soil seed bank (Cao et al., 2012). Dimorphic seeds differ in germination timing (seedlings derived from brown seeds emerged in spring and those from black seeds in summer), but seedling recruitment and survival percentages were almost the same (Cao et al., 2012; Yang et al., 2015a).

\section{MATERIALS AND METHODS}

\section{Field Site Description}

Both populations of Suaeda corniculata occur around shores of saline lakes. Population 1 (P1) is distributed in a saline steppe on the Ordos Plateau of Inner Mongolia, northcentral China $\left(38^{\circ} 14^{\prime} \mathrm{N}, 107^{\circ} 29^{\prime} \mathrm{E}, 1311 \mathrm{~m}\right.$ a.s.l.), where mean annual precipitation is $249.8 \mathrm{~mm}$ and mean annual temperature $8.2^{\circ} \mathrm{C}$. Population 2 (P2) occurs in a cold desert of the Junggar Basin of Xinjiang, northwest China $\left(43^{\circ} 43^{\prime} \mathrm{N}, 87^{\circ} 37^{\prime} \mathrm{E}, 429 \mathrm{~m}\right.$ a.s.l). This area also has a semi-arid climate with a mean annual precipitation of $286.2 \mathrm{~mm}$ and a mean annual temperature of $6.9^{\circ} \mathrm{C}$ (CMDSSS, 2015). P1 has a distinct autumn/winter/early spring dry season with most of the precipitation occurring in late-spring/summer and peaking in July-August (CMDSSS, 2015). P2 has a similar precipitation pattern but with relatively more precipitation in autumn/winter/early spring and with rainfall peaking earlier in the summer than in P1 (Figure 1).

\section{In Situ Differences between the Two Study Populations}

This part of the study was done to verify (or not) differences in the two study populations in situ in order to better compare their responses to salt stress in a pot experiment (for experimental design of the study see Figure 2). Four soil cores (each $5 \mathrm{~cm}$ length $\times 5 \mathrm{~cm}$ width $\times 20 \mathrm{~cm}$ depth) were collected from P1 or P2 in mid-October (2010 and 2011 for P1; 2010 and 2012 for $\mathrm{P} 2$ ), and the soil cores were sub-divided in to four layers: $0-5 \mathrm{~cm}$, $5-10 \mathrm{~cm}, 10-15 \mathrm{~cm}, 15-20 \mathrm{~cm}$. Mean total soil salinity in the $0-20 \mathrm{~cm}$ soil layer were determined by soil salinities of the 16 soil samples ( 4 cores $\times 4$ layers) by using the residue drying quality method (Bao, 2000). Twenty individual plants in each natural population were haphazardly selected to determined life history 


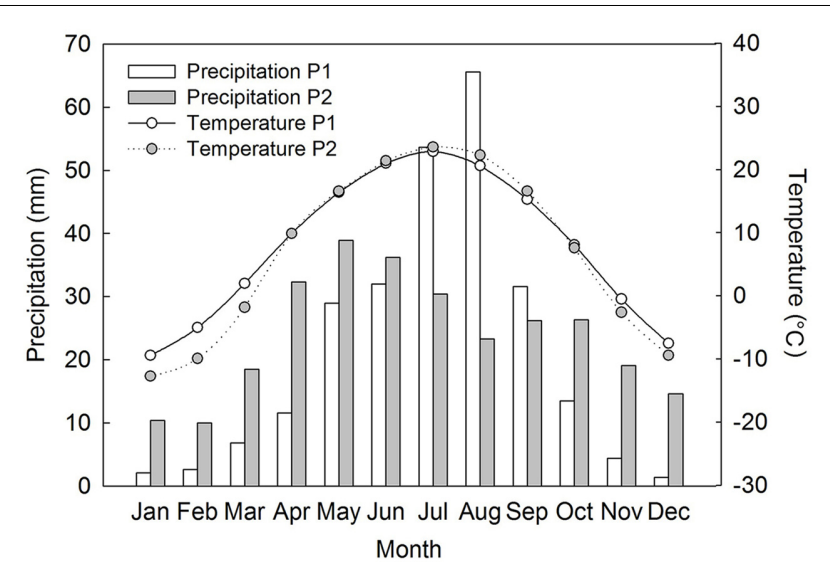

FIGURE 1 | Recent 30 years of precipitation and mean air temperature data at the two field study sites of Suaeda corniculata (CMDSSS, 2015). P1, population 1; P2, population 2.

traits, including life span, plant height, reproductive allocation, seed morph ratio, seed size, and germination percentage.

\section{Common Environment Experiment}

Mature seeds used in the experiment were collected from several hundred plants on 20 October 2012 from P1 and on 25 September 2012 from P2. Seeds were dried for 10 days at room conditions (10-18 $\left.{ }^{\circ} \mathrm{C}, 17-32 \% \mathrm{RH}\right)$ and sorted into brown and black morphs. Then, the seeds were put into cloth bags and buried in soil at a depth of $2 \mathrm{~cm}$ near the experimental site until used in a common environment experiment, which was begun in spring 2013. Thus, the seeds were cold stratified during winter 2012/2013 before the experiments were begun in spring 2013.

The common environment experiment was conducted in two well-ventilated screen houses (one for P1 and the other for P2) at Ordos Sandland Ecological Research Station of the Chinese Academy of Sciences $\left(39^{\circ} 29^{\prime} \mathrm{N}, 110^{\circ} 11^{\prime} \mathrm{E}, 1300 \mathrm{~m}\right.$ a.s.l.). The houses were covered with sheets of plastic only during rains. Seeds of the two morphs from each population were sown into 12-cm-diameter $\times 20$-cm-tall plastic pots on 20 May 2013. Pots were filled with vermiculite and sand $(2 \mathrm{~L}, 1: 1, \mathrm{v} / \mathrm{v})$ to which was added $6 \mathrm{~g}$ of sustained release fertilizer (Osmocote 5\#, Scotts, Marysville, $\mathrm{OH}$, United States, with a 14 N: 13 P: 13 K elemental ratio, duration 5-6 months). Plants from P1 and P2 were kept in separate houses (about $32 \mathrm{~m}$ away from each other) to prevent cross pollination between them. Plants of each population were arranged randomly, and they were assumed to be pollinated by the same pollen pool of their population (Latzel et al., 2014), and the position differences of plants in house could be excluded.

Addition of salt was begun about three weeks after the sowing date, when all seedlings had established. Only $\mathrm{NaCl}$ was used to regulate soil salinity, because it is the major component of soil salinity in the study areas of the two populations (content of main ions in soil was determined by an inductive coupled plasma emission spectrometer, ICAP6300 (Dionex, Sunnyvale, CA, United States) and an ion chromatograph, ICS-1500 (Thermo Scientific, Waltham, MA, United States) in 2010). Pots received $500 \mathrm{~mL}$ of (1) tap water $\left(0 \mathrm{~mol} \cdot \mathrm{L}^{-1} \mathrm{NaCl}\right.$; control $)$, (2) $0.1 \mathrm{~mol} \cdot \mathrm{L}^{-1} \mathrm{NaCl}$ solution, (3) $0.2 \mathrm{~mol} \cdot \mathrm{L}^{-1} \mathrm{NaCl}$ solution, (4) $0.4 \mathrm{~mol} \cdot \mathrm{L}^{-1}$, (5) $0.6 \mathrm{~mol} \cdot \mathrm{L}^{-1}$, or (6) $1.2 \mathrm{~mol} \cdot \mathrm{L}^{-1}$ once per week. To avoid the risk of drought stress, $200 \mathrm{~mL}$ of tap water were applied to each pot per week during spring and autumn and $300 \mathrm{~mL}$ per week during summer. Salt addition lasted for eight weeks, during which time soil salinity in the pots reached $0 \mathrm{~mol} \cdot \mathrm{L}^{-1}, 0.2 \mathrm{~mol} \cdot \mathrm{L}^{-1}, 0.4 \mathrm{~mol} \cdot \mathrm{L}^{-1}, 0.8 \mathrm{~mol} \cdot \mathrm{L}^{-1}$, or $1.2 \mathrm{~mol} \cdot \mathrm{L}^{-1}$ in salt additions $1,2,3,4$, and 5 , respectively. However, plants did not survive under a salinity of $1.2 \mathrm{~mol} \cdot \mathrm{L}^{-1}$, and thus we could not collect any data for this treatment. Therefore, by the end of 2013 we had produced 16 categories and 160 individuals of maternal plants: 2 populations $\times 2$ seed morphs (from which maternal plants were produced) $\times 4$ soil salinities $\times 10$ replicates. Each plant was harvested when it turned yellow, and the seeds were beginning to disperse.

\section{Key Life History Stages of Plants Grown in Common Environment Experiment}

Seedling stage, vegetative period, reproductive period and life span were recorded by monitoring the following phenological
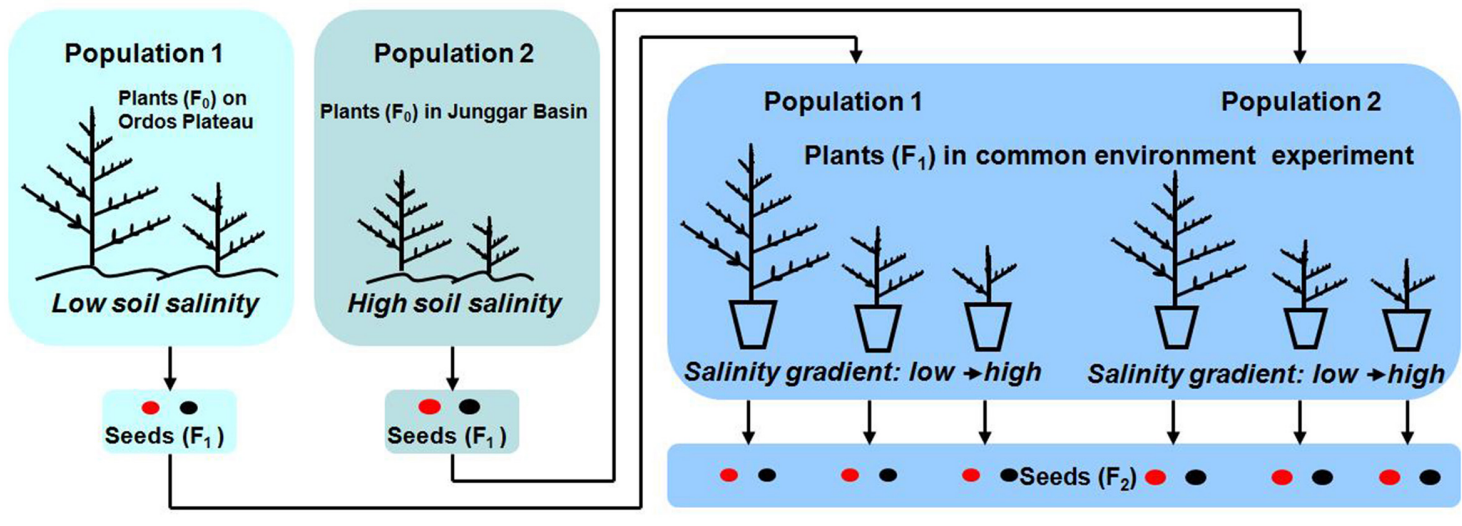

FIGURE 2 | Experimental design of study. 
events for $F_{1}$ seeds and $F_{1}$ plants (see Figure 2): (1) germination; (2) emergence of first branch from main stem, which indicates seedlings have established; (3) opening of first flower, which indicates the shift from vegetative growth to reproductive growth; and (4) dispersal of seeds, which indicates seeds have matured. Thus, the seedling stage was from (1) to (2), the vegetative period (1) to (3), the reproductive period (3) to (4) and plant life span (1) to (4).

\section{Vegetative and Reproductive Traits of Plants Grown in Common Environment Experiment}

Vegetative mass and reproductive mass (total seed mass per plant) were measured after harvest of $F_{1}$ plants (see Figure 2). Each plant was separated into vegetative (shoots) and reproductive (seeds) parts. After oven-drying at $75^{\circ} \mathrm{C}$ for $48 \mathrm{~h}$, vegetative parts were weighed using a Sartorius BP 221 electronic balance (Sartorius AG, Gottingen, Germany) (0.0001 g). Reproductive mass was determined after drying for 10 days in room conditions.

\section{Traits of Seeds Produced in Common Environment Experiment}

One-thousand seeds $\left(\mathrm{F}_{2}\right.$, see Figure 2$)$ were randomly selected from each $F_{1}$ plant to determine the proportion of brown seeds (number of brown seeds/total number of seeds; proportion of black seeds $=1$ - proportion of brown seeds). If the number of seeds per plant was less than 1000, we counted all of them. We measured seed diameter and 1000-seed mass of each seed morph using a Nikon $80 \mathrm{i}$ dissecting microscope equipped with a micrometer (Nikon Corporation, Tokyo, Japan) and the Sartorius electronic analytical balance, respectively. The number of seeds was calculated as reproductive mass per plant divided by 1000 seed mass multiplied by 1000 .

Germination percentage of the $\mathrm{F}_{2}$ seeds produced by these $F_{1}$ experimental plants was assessed. There were 32 categories of seeds ( 2 seed morphs of offspring seeds $\times 16$ categories of maternal plants, see above), 128 Petri dishes (32 categories of seeds $\times 4$ replicates) and 3200 seeds (25 seeds per Petri dish). Fresh brown and black offspring seeds were incubated on Whatman No.1 filter paper in $5-\mathrm{cm}$-diameter Petri dishes moistened with distilled water at $10 / 25^{\circ} \mathrm{C}(12 \mathrm{~h}$ darkness $/ 12 \mathrm{~h}$ fluorescent light). The germination test lasted 3 weeks, by which time germination percentages had leveled off. The criterion for germination was emergence of the radicle. Germination was monitored every $24 \mathrm{~h}$, and germinated seeds were removed at each count. After the germination test, non-germinated seeds were tested for viability with tetrazolium (Baskin and Baskin, 2014), and the germination percentage was calculated as the number of germinated seeds divided by (25 - dead seeds) multiplied by $100 \%$.

\section{Statistical Analyses}

The effects of population (P), salinity (S) and seed morph (SM) on phenology, plant height, biomass and seed traits were analyzed using three-way ANOVA, and the effects of P and SM on the length of seedling stage were analyzed using two-way ANOVA. These statistical analyses were performed with SPSS Version 17.0 (SPSS Inc., Chicago, IL, United States), and data were squareroot or arcsine transformed when necessary to meet assumptions of ANOVA. Tukey's HSD test was used to determine differences $(P<0.05)$ between individual treatments. Independent-samples $t$-test was used to compare significance $(P<0.05)$ in field data between the two populations.

\section{RESULTS}

\section{In Situ Differences between the Two Study Populations}

P1 soil was less saline than that of P2 (Table 1). Plants $\left(\mathrm{F}_{0}\right)$ growing in their natural habitat (P1 vs. P2) differed in life history traits (life span, plant height and reproductive allocation) and in seed $\left(\mathrm{F}_{0}\right)$ traits (brown seed proportion, seed diameter and germination percentage). Plants at P2 (more-saline site) were smaller and had higher reproductive allocation, higher brown seed proportion, larger seeds and lower germination percentage of black seeds than those at P1 (less-saline site) (Table 1).

\section{Key Life History States of Plants $\left(F_{1}\right)$ Grown in Common Environment Experiment}

Population, salinity and their interactions all had a significant effect on the length of three key life history stages (vegetative period, reproductive period and life span), but seed morph had an effect only on length of the vegetative period (Table 2). The life span of P1 was longer than that of P2, and this was mostly due to $\mathrm{P} 1$ having a longer vegetative period than that of P2 (Figures 3A,B). However, the length of the reproductive period of P1 was shorter than that of P2 (Figures 3A,B). The length of vegetative period, reproductive period and life span was almost the same among different salinities (from 0.2 to $0.8 \mathrm{~mol} \cdot \mathrm{L}^{-1}$ ), except for $0 \mathrm{~mol} \cdot \mathrm{L}^{-1}$ (control), where plants had the longest vegetative stage but the shortest reproductive period and life span (Figures 3A,B). The seedling stage of plants from brown seeds was shorter than that for black seeds. This indicates that seedlings developed from brown seeds established more rapidly than those from black seeds (Figures 3A,B).

\section{Vegetative and Reproductive Traits of Plants $\left(F_{1}\right)$ Grown in Common Environment Experiment}

Biomass was significantly affected by population and salinity but not by seed morph (Table 2). Plants produced the most biomass under $0.2 \mathrm{~mol} \cdot \mathrm{L}^{-1}$ salinity, and the total, vegetative and reproductive mass decreased with a further increase in salinity (Figures 4A,B). Reproductive allocation (reproductive mass/total biomass) increased with level of salinity. From 0 to $0.8 \mathrm{~mol} \cdot \mathrm{L}^{-1}$, reproductive allocation increased $16 \%$ for $\mathrm{P} 1$ and $12 \%$ for $\mathrm{P} 2$. In addition, plants had the lowest reproductive allocation under $0 \mathrm{~mol} \cdot \mathrm{L}^{-1}$ ( $4 \%$ for $\mathrm{P} 1$ vs. $24 \%$ for P2). 
Total plant biomass of P1 was larger than that of P2, which mostly was due to P1 having a larger vegetative mass than P2. However, P1 produced fewer seeds (less reproductive mass) than P2 (Figures 4A,B), which resulted in lower reproductive allocation in $\mathrm{P} 1$ than in $\mathrm{P} 2$.

\section{Traits of Seeds Produced in Common Environment Experiment}

Plants grown under $0.2 \mathrm{~mol} \cdot \mathrm{L}^{-1}$ salinity produced the greatest number of seeds, and seed number decreased with an increase in salinity (Supplementary Figure S1). The proportion of seed morphs produced by the plants was significantly influenced by population, salinity and morph of the maternal seeds from which plants were grown (Table 2). The brown seed proportion produced by $\mathrm{P} 1$ plants was lower than that produced by $\mathrm{P} 2$ plants (Figures 5A,B). The proportion of brown seeds was lowest under $0.2 \mathrm{~mol} \cdot \mathrm{L}^{-1}$ salinity and increased with an increase in salinity (Figures 5A,B). For plants grown under 0.2 to $0.8 \mathrm{~mol} \cdot \mathrm{L}^{-1}$, the proportion of brown seeds increased $19.8 \%$ for P1 and $16.2 \%$ for P2 (Figures 5A,B).

Diameter of the two seed morphs produced by the experimental plants was significantly affected by population, salinity and maternal seed morph (Table 2). For both seed morphs, seeds of P1 were smaller than those of P2 (Supplementary Figure S2). Both brown and black seeds were larger when their maternal plants were grown in $0.2 \mathrm{~mol} \cdot \mathrm{L}^{-1}$ or $0.4 \mathrm{~mol} \cdot \mathrm{L}^{-1}$, whereas plants grown in $0 \mathrm{~mol} \cdot \mathrm{L}^{-1}$ produced the smallest seeds (Supplementary Figure S2).

For both populations, brown seeds germinated to a high percentage $(>85 \%)$ in all maternal salinity concentrations (Figures 6A,C), whereas germination of black seeds differed between populations and maternal salinities (Table 2). Germination percentage of black seeds was higher for P1 than for P2. Black seeds of P1 germinated to $100 \%$ only in $0 \mathrm{~mol} \cdot \mathrm{L}^{-1}$ maternal salinity, whereas germination of black seeds of $\mathrm{P} 2$ reached only about $70 \%$ (Figures 6B,D). Maternal salt stress reduced germination of black seeds (Figures 6A-D).

\section{DISCUSSION}

The present study asked if there are phenotypic differences in life history traits between two populations of Suaeda corniculata. To minimize carryover effects from field environments, plants from the two seed morphs derived from field populations were grown in a common environment. Distinct phenotypic differences between populations in the field were retained in the common environment. Indeed, seed morph ratio and germination percentage of dimorphic seeds differed greatly between magnitudes of soil salinity. Although many studies have tested the effects of soil salinity on a limited number of plant life history traits (Yao et al., 2010; Wang et al., 2012, 2015), our study appears to be the first to clearly detail the phenotypically plastic response of heteromorphic seeds to different levels of salinity by cultivating plants from different geographic populations in a common environment.

Soil salinity in arid and semi-arid zones has been considered both an extreme environmental stress and a source of disturbance to plants (Ungar, 1978; Khan and Ungar, 2001; Imbert, 2002), and halophytes have morphological and physiological adaptations that facilitate their survival and growth under such harsh conditions (Debez et al., 2004; Yang et al., 2010). Plants of the seed-dimorphic species Suaeda splendens grew better at $0.2 \mathrm{~mol} \cdot \mathrm{L}^{-1} \mathrm{NaCl}$ than in pure water (Redondo-Gómez et al., 2008), and the optimum growth of Salicornia dolichostachya was at $0.3 \mathrm{~mol} \cdot \mathrm{L}^{-1} \mathrm{NaCl}$ (Katschnig et al., 2013). Likewise, in the present study $\mathrm{F}_{1}$ plants of $S$. corniculata derived from both seed morphs performed better at low salinity than in salt-free tap water. And although a high level of soil salinity had adverse effects on plant growth and seed production, the plants allocated a higher proportion of biomass to seeds under salinity stress.

TABLE 1 | Variation in field between two natural populations of Suaeda corniculata.

\begin{tabular}{|c|c|c|c|}
\hline & Population 1 (Ordos Plateau) & Population 2 (Junggar Basin) & \\
\hline Year 1 & $2.5 \pm 0.1$ & $4.0 \pm 0.3$ & \\
\hline \multirow[t]{2}{*}{ Year 2} & $2.4 \pm 0.2$ & $3.6 \pm 0.5$ & \\
\hline & $\left(419 \pm 9 \mathrm{mmol} \cdot \mathrm{L}^{-1} \mathrm{NaCl}\right)$ & $\left(624 \pm 55 \mathrm{mmol} \cdot \mathrm{L}^{-1} \mathrm{NaCl}\right)$ & \\
\hline Life span (d) & $149.7 \pm 1.1$ & $137.8 \pm 0.8$ & * \\
\hline Reproductive allocation (\%) & $21.8 \pm 0.8$ & $24.8 \pm 0.8$ & * \\
\hline Brown seed proportion (\%) & $20.4 \pm 4.0$ & $67.2 \pm 2.3$ & * \\
\hline \multicolumn{4}{|l|}{ Seed diameter $(\mathrm{mm})$} \\
\hline Brown & $1.1 \pm 0.0$ & $1.4 \pm 0.0$ & * \\
\hline Black & $1.0 \pm 0.0$ & $1.2 \pm 0.0$ & * \\
\hline \multicolumn{4}{|l|}{ Germination of fresh seeds (\%) } \\
\hline
\end{tabular}

* Significant difference $(P<0.05)$ between populations. 


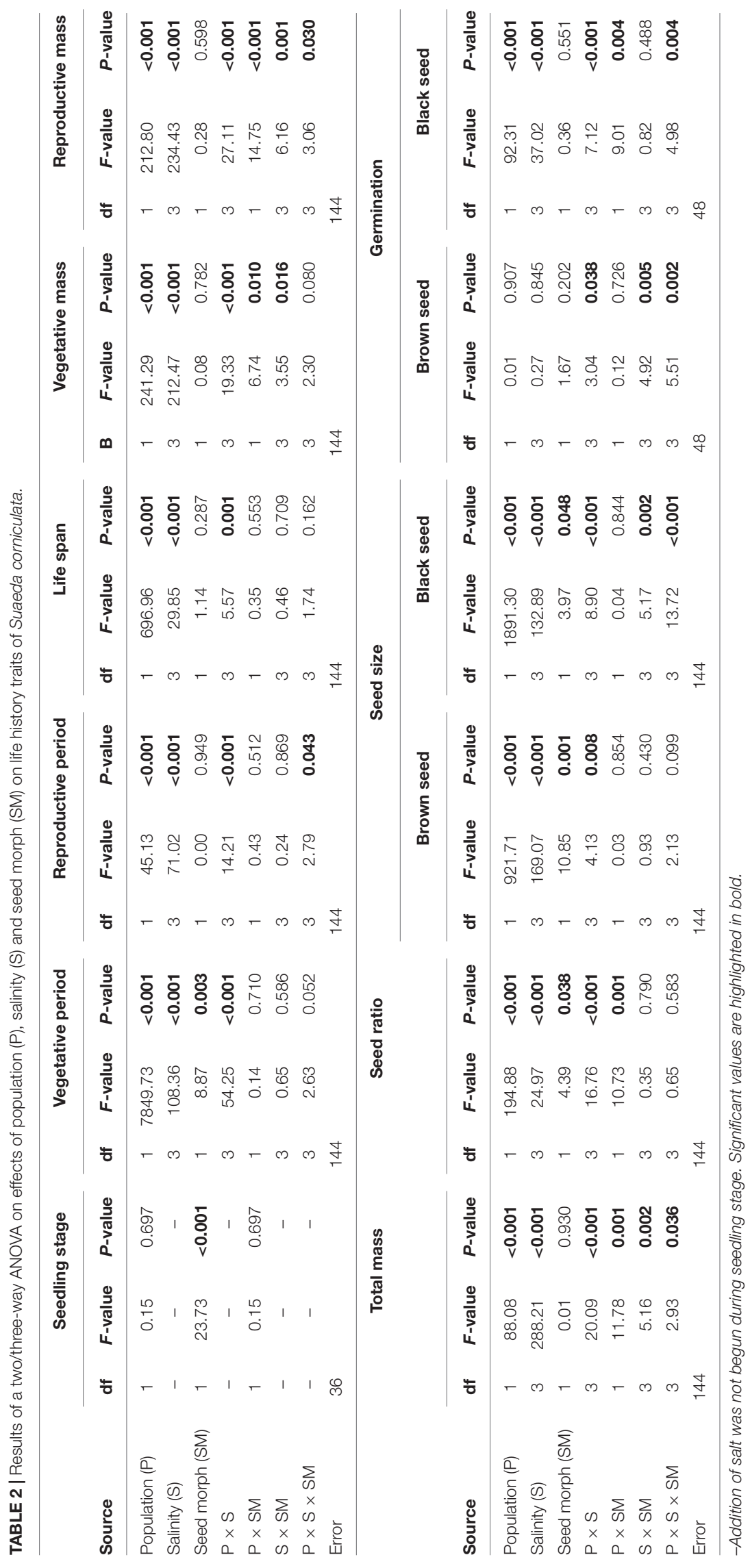




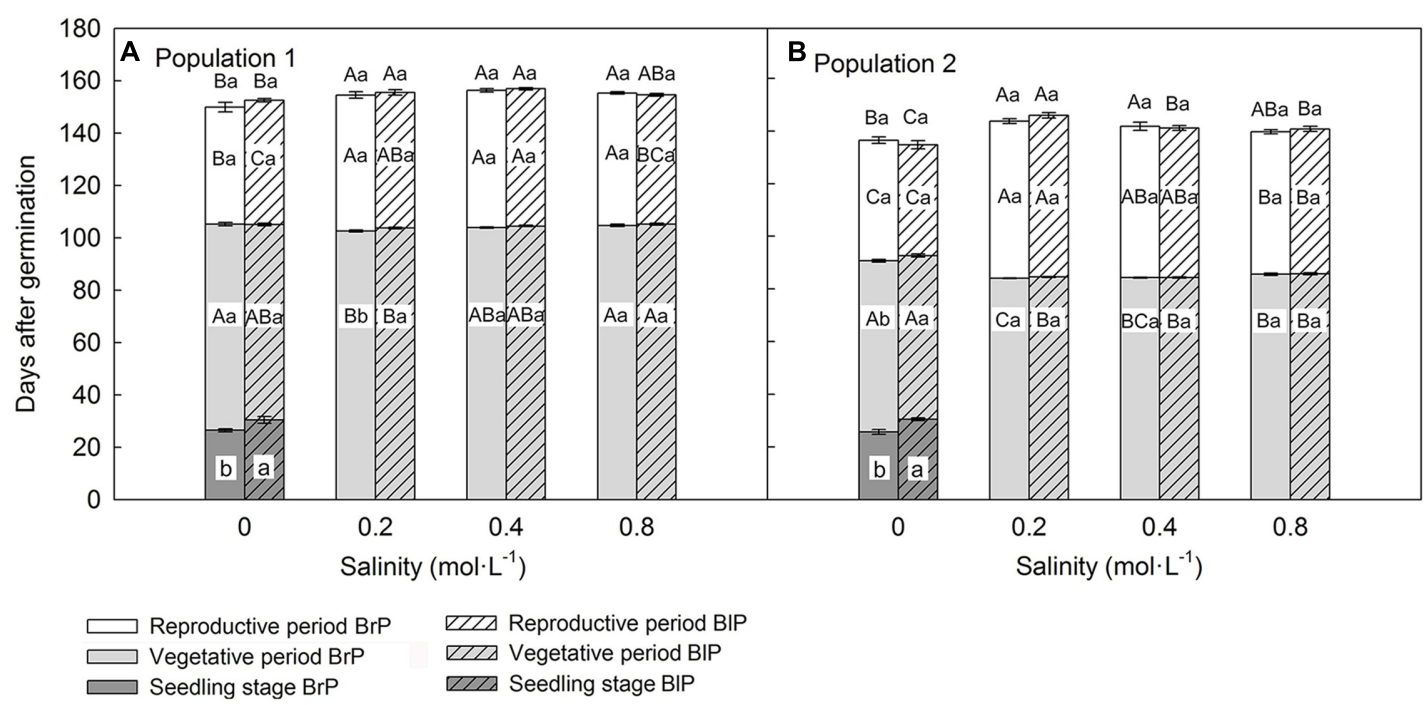

FIGURE 3 | Effects of soil salinity and seed morph on length of key life history stages (mean \pm 1 SE) of $F_{1}$ (filial generation 1 , see Figure 2 ) plants of the two populations of Suaeda corniculata. Different letters above bars indicate significant differences $(P<0.05)$ in length of life span and different letters within bars significant differences $(P<0.05)$ in length of seedling stage, vegetative period, and reproductive period. Uppercase letters indicate differences across all salinity levels in the same seed morph and lowercase letters differences between seed morphs for the same salinity level. BrP, plants from brown seeds; BIP, plants from black seeds. Addition of salt was begun after the seedlings had established, and data for seedling stage were collected under 0 mol. $\mathrm{L}^{-1} \mathrm{NaCl}$.

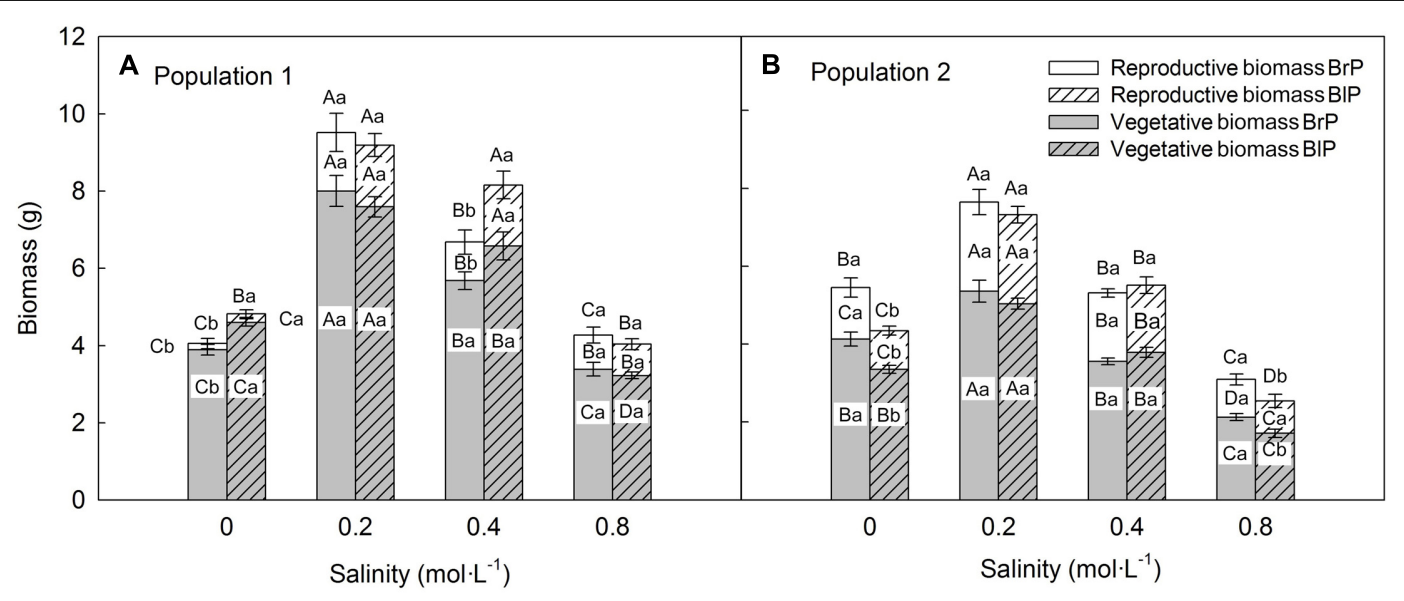

FIGURE 4 | Effects of soil salinity and seed morph on biomass allocation (mean \pm 1 SE) of $F_{1}$ (filial generation 1) plants of the two populations of Suaeda corniculata Different letters above bars indicate significant differences $(P<0.05)$ in total biomass and different letters in bars significant differences $(P<0.05)$ in vegetative or reproductive biomass. Uppercase letters indicate differences across all salinity levels in the same seed morph and lowercase letters differences between seed morphs for the same salinity level. BrP, plants from brown seeds; BIP, plants from black seeds.

Stress can cause a shift in the proportion of biomass allocated to vegetative and reproductive components ( $\mathrm{Lu}$ et al., 2012). These plastic responses in life history traits to stress can be interpreted as to be adaptive because they increase the seed production component of fitness (Primack and Kang, 2005; Lu et al., 2016).

Studies have shown that growth conditions of the mother plant can alter the proportion of different seed morphs produced by an individual plant (reviewed in Baskin and Baskin, 2014), but the results are inconsistent. For example, seed morph ratio was not changed by growth of maternal plants of Suaeda aralocaspica (Amaranthaceae) in different salinities (Wang et al., 2012), whereas high salt stress increased the proportion of (non-dormant) brown seeds of Chenopodium album (Amaranthaceae) (Yao et al., 2010) and of Suaeda salsa (Amaranthaceae) (Wang et al., 2015). In our study, the proportion of brown seeds increased with increased salinity levels in the two populations of S. corniculata, thus agreeing with the results of Yao et al. (2010) and Wang et al. (2015). Because they germinate to high percentages in a wide range of salinities, brown seeds of Amaranthaceae species have been considered to be more 


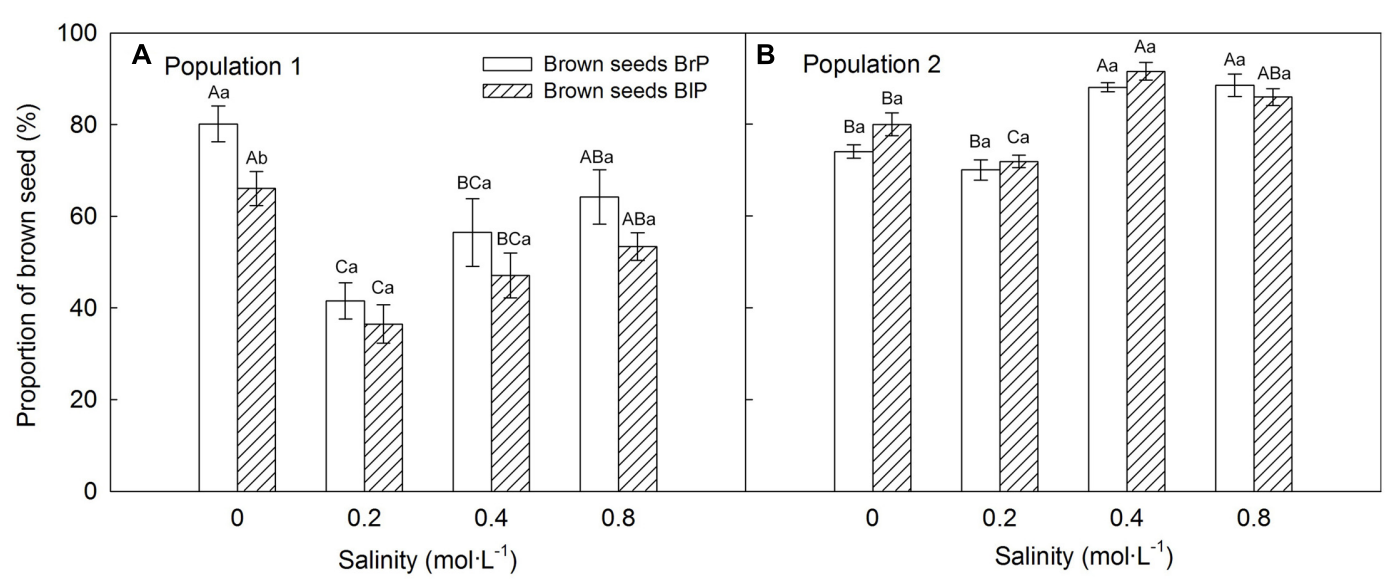

FIGURE 5 | Effects of soil salinity and $F_{1}$ (filial generation 1) seed morph on brown seed proportion (mean \pm 1 SE) produced by $F_{1}$ experimental plants of $S$ uaeda corniculata. Different uppercase letters indicate differences $(P<0.05)$ in brown seed proportion across all salinity levels in the same seed morph and lowercase letters differences $(P<0.05)$ in brown seed proportion between seed morphs for the same salinity level. BrP, plants from brown seeds; BIP, plants from black seeds.

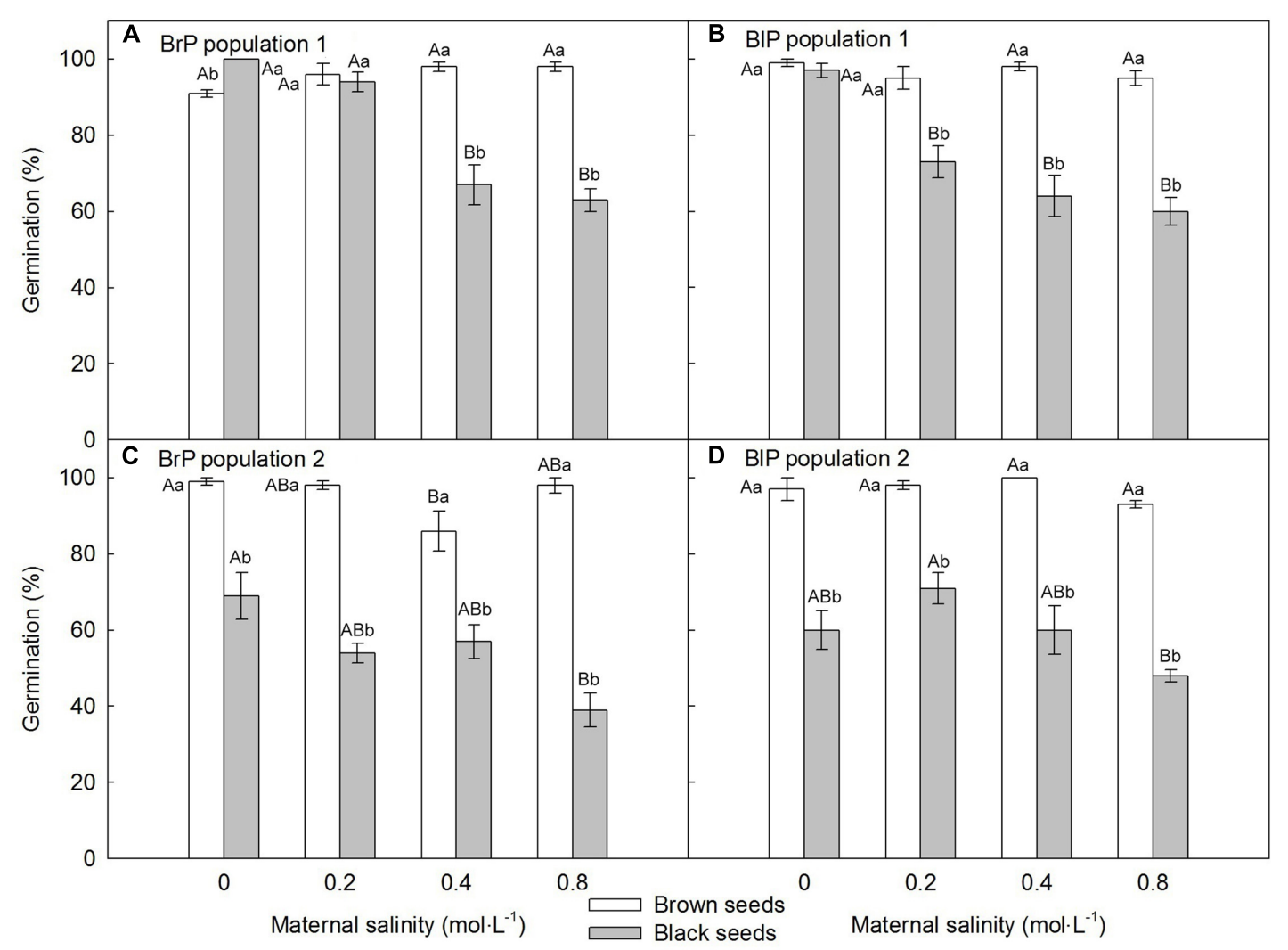

FIGURE 6 | Germination percentage (mean \pm 1 SE) of fresh $F_{2}$ (filial generation 2, see Figure 2) dimorphic seeds produced by $F_{1}$ (filial generation 1) experimental plants of Suaeda corniculata. Different uppercase letters indicate differences $(P<0.05)$ across all salinity levels in the same seed morph and different lowercase letters differences $(P<0.05)$ between seed morphs for the same maternal salinity level. BrP, plants from brown seeds; BIP, plants from black seeds.

fit than black seeds in harsh saline habitats (Khan et al., 2001; Song et al., 2008; Yao et al., 2010; Wang et al., 2015). However, Cao et al. (2012) showed that brown seeds of S. corniculata lost viability easily after exposure to salt stress, whereas black seeds did not. Thus, the ecological significance of brown versus black seeds is highly complex and should not be determined only by germination percentage. Since brown seeds are larger and growth of seedlings derived from them is faster than for black 
seeds, seedlings may benefit from more resources stored in large brown seeds (Grieve and Francois, 1992; Jakobsson and Eriksson, 2000; Easton and Kleindorfer, 2009), which would then lead to faster establishment. Thus, brown seed cohorts may benefit from exploiting temporarily favorable conditions, for example high soil moisture (and thus lower salinity) after rainfall. In which case, they may establish populations rapidly in saline habitats. On the other hand, black seeds of $S$. corniculata cannot germinate at high salinity, but they can form a persistent seed bank, which enables them to persist in the habitat should the entire population die before reproducing in a particular year. Black seed cohorts mainly germinate in the summer rainy season (Cao et al., 2012), and consequently they may be exposed to less harsh conditions for establishment than brown seed cohorts.

Variation in morph ratio and seed size has been found among populations of diaspore-heteromorphic species. For the annual halophyte, Suaeda salsa (Amaranthaceae), brown/black seed ratio and 100-seed mass were significantly higher in the intertidal zone (4.5 and $3.3 \mathrm{~g} \cdot \mathrm{kg}^{-1}, \mathrm{Na}^{+}$and $\mathrm{Cl}^{-}$, respectively) than in an inland saline habitat $\left(2.4\right.$ and $2.0 \mathrm{~g} \cdot \mathrm{kg}^{-1}, \mathrm{Na}^{+}$ and $\mathrm{Cl}^{-}$, respectively) (Song et al., 2008). The proportion of brown seeds and reserve mass (embryo plus perisperm) of black seeds of Chenopodium album were higher in populations on flat ground than that of a population growing on a slope (Yao et al., 2010). However, whether these differences between populations were due to genetics $(\mathrm{G})$, environment (E) or $\mathrm{G} x$ $\mathrm{E}$ interactions was not determined. We conducted a common environment experiment in which $F_{1}$ plants were grown from $F_{1}$ seeds under different salinity levels to distinguish possible genetic differentiation between populations and to demonstrate phenotypic plastic response to different salt concentrations. For S. corniculata, the field investigation and common environment experiments revealed that the differences between populations were significant in both morph ratio and seed size, as well as high salinity increased brown seed proportion but had limited impact on seed size. Quinn and Colosi (1977) suggested that one generation of seed production under the same conditions is required to demonstrate that differences in germination are genetically based. However, we used $F_{1}$ plants for testing post-germination life history traits, and thus the possibility exists that differences among the traits could have been due to some carryover effects on plants grown from $\mathrm{F}_{1}$ seeds (Whittle et al., 2009; Herman et al., 2012; Yang et al., 2015b).

Seed dimorphism in $S$. corniculata may be a bet-hedging strategy since the offspring have two distinct life histories to cope with a variable environment (Venable, 1985a; Simons, 2011). As such, then, it seems that population persistence is more likely for plants producing both brown and black seeds than it would be for them producing either one or the other seed morph. However,

\section{REFERENCES}

Ameixa, O. M. C. C., Marques, B., Fernandes, V. S., Soares, A. M. V. M., Calado, R., and Lillebø, A. I. (2016). Dimorphic seeds of Salicornia ramosissima display contrasting germination responses under different salinities. Ecol. Eng. 87, 120-123. doi: 10.1016/j.ecoleng.2015.11.019 to document bet-hedging and thus to understand the ecological consequences of production of dimorphic seeds, a comparative life history/demographic analysis of each of the two morphs is required (Venable, 1985a,b; Venable and Levin, 1985). It must be shown that the two morphs maximize the geometric mean of the number of offspring (Ro, a measure of fitness) across generations (Simons, 2011) in order to prove that the seed heteromorphism in $S$. corniculata is a bet-hedging strategy.

\section{CONCLUSION}

According to the field investigation and common environment experiments, phenotypic differences between S. corniculata populations are genetically based. Adverse effects of salinity stress are alleviated by the ability of plants to allocate a high proportion of resources to reproduction. Morph production and germination behavior of dimorphic seeds are influenced by the level of soil salinity, suggesting that soil salinity plays an ecologically important role in population regeneration of S. corniculata in the natural habitat.

\section{AUTHOR CONTRIBUTIONS}

$\mathrm{ZH}, \mathrm{FY}, \mathrm{CB}, \mathrm{JB}$, and $\mathrm{XY}$ conceived and designed the experiments. $\mathrm{FY}, \mathrm{DC}$, and $\mathrm{XY}$ performed the experiments and analyzed the data. FY, ZH, CB, and JB wrote the manuscript.

\section{FUNDING}

This work was supported by the Key Basic Research and Development Plan of P. R. China (2016YFC050080502) and the National Natural Science Foundation of P. R. China (31370705, 31570416, 31600331).

\section{ACKNOWLEDGMENT}

We are grateful to Prof. Johannes H. C. Cornelissen, VU University, The Netherlands, for the valuable comments on the manuscript.

\section{SUPPLEMENTARY MATERIAL}

The Supplementary Material for this article can be found online at: http://journal.frontiersin.org/article/10.3389/fpls.2017.01028/ full\#supplementary-material

Bao, S. D. (2000). Soil Chemistry and Agriculture Analysis. Beijing: China Agriculture Press.

Baskin, C. C., and Baskin, J. M. (2014). Seeds: Ecology, Biogeography, and Evolution of Dormancy and Germination, 2nd Edn. San Diego, CA: Elsevier.

Bernstein, L. (1975). Effects of salinity and sodicity on plant growth. Annu. Rev. Phytopathol. 13, 295-312. doi: 10.1146/annurev.py.13.090175.001455 
Cao, D. C., Baskin, C. C., Baskin, J. M., Yang, F., and Huang, Z. Y. (2012). Comparison of germination and seed bank dynamics of dimorphic seeds of the cold desert halophyte Suaeda corniculata subsp. mongolica. Ann. Bot. 110, 1545-1558. doi: 10.1093/aob/mcs205

CMDSSS (2015). China Meteorological Data Sharing Service System. Available at: http://data.cma.cn/site/index.html

Debez, A., Hamed, K. B., Grignon, C., and Abdelly, C. (2004). Salinity effects on germination, growth, and seed production of the halophyte Cakile maritima. Plant Soil 262, 179-189. doi: 10.1023/B:PLSO.0000037034.47247.67

Donohue, K. (2009). Completing the cycle: maternal effects as the missing link in plant life histories. Philos. Trans. R. Soci. B Biol. Sci. 364, 1059-1074. doi: $10.1098 /$ rstb.2008.0291

Easton, L. C., and Kleindorfer, S. (2009). Effects of salinity levels and seed mass on germination in Australian species of Frankenia L. (Frankeniaceae). Environ. Exp. Bot. 65, 345-352. doi: 10.1016/j.envexpbot.2008.10.006

Grieve, C. M., and Francois, L. E. (1992). The importance of initial seed size in wheat plant response to salinity. Plant Soil 147, 197-205. doi: 10.1007/ BF00029071

Gutterman, Y. (2002). Survival Strategies of Annual Desert Plants. Berlin: Springer. doi: 10.1007/978-3-642-55974-7

Harper, J. L. (1977). Population Biology of Plants. New York, NY: Academic Press.

Herman, J. J., Sultan, S. E., Horgan-Kobelski, T., and Riggs, C. (2012). Adaptive transgenerational plasticity in an annual plant: grandparental and parental drought stress enhance performance of seedlings in dry soil. Integr. Comp. Biol. 52, 77-88. doi: 10.1093/icb/ics041

Hoyle, G. L., Steadman, K. J., Good, R. B., McIntosh, E. J., Galea, L. M. E., and Nicotra, A. B. (2015). Seed germination strategies: an evolutionary trajectory independent of vegetative functional traits. Front. Plant Sci. 6:731. doi: 10.3389/ fpls.2015.00731

Huang, Z. Y., Liu, S. S., Bradford, K. J., Huxman, T. E., and Venable, D. L. (2016). The contribution of germination functional traits to population dynamics of a desert plant community. Ecology 97, 250-261.

Imbert, E. (2002). Ecological consequences and ontogeny of seed heteromorphism. Perspect. Plant Ecol. Evol. Syst. 5, 13-36. doi: 10.1078/1433-8319-00021

Jakobsson, A., and Eriksson, O. (2000). A comparative study of seed number, seed size, seedling size and recruitment in grassland plants. Oikos 88, 494-502. doi: 10.1034/j.1600-0706.2000.880304.x

Katschnig, D., Broekman, R., and Rozema, J. (2013). Salt tolerance in the halophyte Salicornia dolichostachya Moss: growth, morphology and physiology. Environ. Exp. Bot. 92, 32-42. doi: 10.1016/j.envexpbot.2012.04.002

Khan, M. A., and Gul, B. (2006). "Halophyte seed germination," in Ecophysiology of High Salinity Tolerant plants, eds M. A. Khan and D. J. Weber (Dordrecht: Springer), 11-30. doi: 10.1007/1-4020-4018-0_2

Khan, M. A., Gul, B., and Weber, D. J. (2001). Germination of dimorphic seeds of Suaeda moquinii under high salinity stress. Aust. J. Bot. 49, 185-192. doi: 10.1071/BT00020

Khan, M. A., and Ungar, I. A. (2001). Alleviation of salinity stress and the response to temperature in two seed morphs of Halopyrum mucronatum (Poaceae). Aust. J. Bot. 49, 777-783. doi: 10.1071/BT01014

Ladiges, P. Y., Foord, P. C., and Willis, R. (1981). Salinity and waterlogging tolerance of some populations of Melaleuca ericifolia Smith. Aust. J. Ecol. 6, 203-215. doi: 10.1111/j.1442-9993.1981.tb01291.x

Latzel, V., Janeèek, Š., Doležal, J., Klimešová, J., and Bossdorf, O. (2014). Adaptive transgenerational plasticity in the perennial Plantago lanceolata. Oikos 123, 41-46. doi: 10.1111/j.1600-0706.2013.00537.x

Lomonosova, M., Brandt, R., and Freitag, H. (2008). Suaeda corniculata (Chenopodiaceae) and related new taxa from Eurasia. Willdenowia 38, 81-109. doi: 10.3372/wi.38.38105

Lu, J. J., Tan, D. Y., Baskin, C. C., and Baskin, J. M. (2016). Effects of germination season on life history traits and on transgenerational plasticity in seed dormancy in a cold desert annual. Sci. Rep. 6:25076. doi: 10.1038/srep25076

Lu, J. J., Tan, D. Y., Baskin, J. M., and Baskin, C. C. (2012). Phenotypic plasticity and bet-hedging in a heterocarpic winter annual/spring ephemeral cold desert species of Brassicaceae. Oikos 121, 357-366. doi: 10.1111/j.1600-0706.2011. 19800.x

Mandák, B., and Pyšek, P. (1999). Effects of plant density and nutrient levels on fruit polymorphism in Atriplex sagittata. Oecologia 119, 63-72. doi: 10.1007/ s004420050761
Mandák, B., and Pyšek, P. (2005). How does seed heteromorphism influence the life history stages of Atriplex sagittata (Chenopodiaceae)? Flora 200, 516-526. doi: 10.1016/j.flora.2005.06.003

Mohamed-Yasseen, Y., Barringer, S. A., Splittstoesser, W. A., and Costanza, S. (1994). The role of seed coats in seed viability. Bot. Rev. 60, 426-439. doi: 10.1007/BF02857926

Pandolfi, C., Mancuso, S., and Shabala, S. (2012). Physiology of acclimation to salinity stress in pea (Pisum sativum). Environ. Exp. Bot. 84, 44-51. doi: 10.1016/ j.envexpbot.2012.04.015

Primack, R. B., and Kang, H. (2005). Measuring fitness and natural selection in wild plant populations. Annu. Rev. Ecol. Syst. 20, 367-396. doi: 10.1146/annurev.es. 20.110189.002055

Quinn, J. A., and Colosi, J. C. (1977). Separating genotype from environment in germination ecology studies. Am. Midl. Nat. 97, 484-489. doi: 10.2307/2425113

Redondo-Gómez, S., Mateos-Naranjo, E., Cambrollé, J., Luque, T., Figueroa, M. E., and Davy, A. J. (2008). Carry-over of differential salt tolerance in plants grown from dimorphic seeds of Suaeda splendens. Ann. Bot. 102, 103-112. doi: 10.1093/aob/mcn069

Redondo-Gómez, S., Wharmby, C., Castillo, J. M., Mateos-Naranjo, E., Luque, C. J., de Cires, A., et al. (2006). Growth and photosynthetic responses to salinity in an extreme halophyte, Sarcocornia fruticosa. Physiol. Plant. 128, 116-124. doi: 10.1111/j.1399-3054.2006.00719.x

Ruiz de Clavijo, E. (2005). The reproductive strategies of the heterocarpic annual Calendula arvensis (Asteraceae). Acta Oecol. 28, 119-126. doi: 10.1016/j.actao. 2005.03.004

Simons, A. M. (2011). Modes of response to environmental change and the elusive empirical evidence for bet hedging. Proc. R. Soc. B Biol. Sci. 278, 1601-1609. doi: 10.1098/rspb.2011.0176

Song, J., Fan, H., Zhao, Y. Y., Jia, Y. H., Du, X. H., and Wang, B. S. (2008). Effect of salinity on germination, seedling emergence, seedling growth and ion accumulation of a euhalophyte Suaeda salsa in an intertidal zone and on saline inland. Aquat. Bot. 88, 331-337. doi: 10.1016/j.aquabot.2007.11.004

Sorensen, A. E. (1978). Somatic polymorphism and seed dispersal. Nature 276, 174-176. doi: 10.1038/276174a0

Ungar, I. A. (1978). Halophyte seed germination. Bot. Rev. 44, 233-264. doi: $10.1007 / \mathrm{BF} 02919080$

Ungar, I. A. (1987). Population ecology of halophyte seeds. Bot. Rev. 53, 301-334. doi: $10.1007 / \mathrm{BF} 02858320$

Venable, D. L. (1985a). The evolutionary ecology of seed heteromorphism. Am. Nat. 126, 577-595. doi: 10.1086/284440

Venable, D. L. (1985b). Ecology of achene dimorphism in Heterotheca latifolia. III. Consequences of varied water availability. J. Ecol. 73, 757-763.

Venable, D. L., Burquez, A., Corral, G., Morales, E., and Espinosa, F. (1987). The ecology of seed heteromorphism in Heterosperma pinnatum in central Mexico. Ecology 68, 65-76. doi: 10.2307/1938805

Venable, D. L., Dyreson, E., and Morlaes, E. (1995). Population dynamic consequences and evolution of seed traits of Heterosperma pinnatum (Asteraceae). Am. J. Bot. 82, 410-420. doi: 10.2307/2445587

Venable, D. L., and Levin, D. A. (1985). Evolutionary ecology of achene dimorphism in Heterotheca latifolia. II. Demographic variation within populations. J. Ecol. 73, 743-755. doi: 10.2307/2260143

Wang, F. X., Xu, Y. G., Wang, S., Shi, W. W., Liu, R. R., Feng, G., et al. (2015). Salinity affects production and salt tolerance of dimorphic seeds of Suaeda salsa. Plant Physiol. Biochem. 95, 41-48. doi: 10.1016/j.plaphy.2015. 07.005

Wang, L., Baskin, J. M., Baskin, C. C., Cornelissen, J. H. C., Dong, M., and Huang, Z. Y. (2012). Seed dimorphism, nutrients and salinity differentially affect seed traits of the desert halophyte Suaeda aralocaspica via multiple maternal effects. BMC Plant Biol. 12:170. doi: 10.1186/1471-2229-12-170

Wang, L., Huang, Z. Y., Baskin, C. C., Baskin, J. M., and Dong, M. (2008). Germination of dimorphic seeds of the desert annual halophyte Suaeda aralocaspica (Chenopodiaceae), a $\mathrm{C}_{4}$ plant without Kranz Anatomy. Ann. Bot. 102, 757-769. doi: 10.1093/aob/mcn 158

Whittle, C. A., Otto, S. P., Johnston, M. O., and Krochko, J. E. (2009). Adaptive epigenetic memory of ancestral temperature regime in Arabidopsis thaliana. Botany 87, 650-657. doi: 10.1139/B09-030

Yang, F., Baskin, J. M., Baskin, C. C., Yang, X. J., Cao, D. C., and Huang, Z. Y. (2015a). Effects of germination time on seed morph ratio in a seed-dimorphic 
species and possible ecological significance. Ann. Bot. 115, 134-145. doi: 10. 1093/aob/mcu210

Yang, F., Yang, X. J., Baskin, J. M., Baskin, C. C., Cao, D. C., and Huang, Z. Y. (2015b). Transgenerational plasticity provides ecological diversity for a seed heteromorphic species in response to environmental heterogeneity. Perspect. Plant Ecol. Evol. Syst. 17, 201-208. doi: 10.1016/j.ppees.2015.03.003

Yang, X. J., Baskin, J. M., Baskin, C. C., Zhang, W. H., and Huang, Z. Y. (2012), Degradation of seed mucilage by soil microflora promotes early seedling growth of a desert sand dune plant. Plant Cell Environ. 35, 872-883. doi: 10.1111/j. 1365-3040.2011.02459.x

Yang, X. J., Dong, M., and Huang, Z. Y. (2010). Role of mucilage in the germination of Artemisia sphaerocephala (Asteraceae) achenes exposed to osmotic stress and salinity. Plant Physiol. Biochem. 48, 131-135. doi: 10.1016/j.plaphy.2009.12.006

Yao, S. X., Lan, H. Y., and Zhang, F. C. (2010). Variation of seed heteromorphism in Chenopodium album and the effect of salinity stress on the descendants. Ann. Bot. 105, 1015-1025. doi: 10.1093/aob/mcq060
Zhu, G. L., Mosyakin, S. L., and Clemant, S. E. (2003). "Chenopodiaceae," in Flora of China, eds Z. Wu, P. H. Raven, and D. Hong (Beijing: Science Press), 351-414.

Zhu, J. K. (2001). Plant salt tolerance. Trends Plant Sci. 6, 66-71. doi: 10.1016/ S1360-1385(00)01838-0

Conflict of Interest Statement: The authors declare that the research was conducted in the absence of any commercial or financial relationships that could be construed as a potential conflict of interest.

Copyright (๑) 2017 Yang, Baskin, Baskin, Yang, Cao and Huang. This is an openaccess article distributed under the terms of the Creative Commons Attribution License (CC BY). The use, distribution or reproduction in other forums is permitted, provided the original author(s) or licensor are credited and that the original publication in this journal is cited, in accordance with accepted academic practice. No use, distribution or reproduction is permitted which does not comply with these terms. 